\title{
A COMPREENSÃO DO TEMOR COMO MODO DE DISPOSIÇÃO DA MULHER COM HIV/AIDS DIANTE DA (IM)POSSIBILIDADE DE AMAMENTAR ${ }^{1}$ \\ UNDERSTANDING FEAR AS A MANNER OF DISPOSITION FOR WOMEN WITH HIV/AIDS BEFORE THE (IM)POSSIBILITY OF BREAST-FEEDING \\ LA COMPRENSIÓN DEL TEMOR COMO MODO DE DISPOSICIÓN DE LA MUJER CON VIH/ SIDA ANTE LA (IM)POSIBILIDAD DE AMAMANTAR
}

\author{
Stela Maris de Mello Padoin², Ívis Emília de Oliveira Souza ${ }^{3}$
}

\begin{abstract}
${ }^{1}$ Artigo construído a partir de um recorte da pesquisa "O cotidiano da mulher com HIV/ Aids diante da (im)possibilidade de amamentar: um estudo na perspectiva heideggeriana", desenvolvida como tese de doutorado e defendida em maio de 2006.

${ }^{2}$ Doutora em Enfermagem. Professor Adjunto do Departamento de Enfermagem da Universidade Federal de Santa Maria. Rio Grande do Sul, Brasil.

${ }^{3}$ Doutora em Enfermagem. Professor Titular de Enfermagem Obstétrica do Departamento de Enfermagem Materno Infantil - Escola de Enfermagem Anna Nery da Universidade Federal do Rio de Janeiro. Orientadora da tese. Rio de Janeiro, Brasil.
\end{abstract}

PALAVRAS-CHAVE: Enfermagem. Saúde da mulher. Síndrome da imunodeficiência adquirida. Aleitamento materno.

KEYWORDS: Nursing. Women's health. Acquired immunodeficiency syndrome. Breast feeding;

RESUMO: Este estudo objetivou desvelar o temor como modo de disposição da mulher com o vírus da imunodeficiência humana no cotidiano da (im)possibilidade de amamentar. Trata-se de pesquisa qualitativa com abordagem fenomenológica, desenvolvida no Hospital Universitário de Santa Maria - RS. Foram realizadas 12 entrevistas, no período de setembro 2004 a março de 2005. A análise se deu conforme o método Heideggeriano. Nos resultados tem-se que a partir da descoberta de sua condição sorológica, a mulher mostra-se no modo determinado do temor em suas variações de pavor, horror e terror. Conclui-se que no mundo do cuidado tem-se a possibilidade de ajudá-la nessa situação vivida de enfrentar não só o diagnóstico de sorologia positiva, como também as implicações do movimento existencial do temor decorrentes dessa condição, buscando desenvolver um cuidado solícito.

ABSTRACT: This study aimed to unveil fear as a manner of disposition for woman with Acquired Immuno-Deficiency Syndrome in daily routines of the (im)possibility of breastfeeding. This qualitative study with a phenomenological approach was developed at University Hospital in Santa Maria - RS, Brazil. Twelve interviews were conducted from September, 2004 to March, 2005. The analysis was based upon Martin Heidegger's method. The results pointed out that starting from the discovery about their serologic condition; they revealed themselves to be determined from fear in their variances of fright, horror, and terror. In conclusion, in the world of the care, there is the possibility to help them to face up to, not only their diagnosis, but also the implications of the existential movement of fear resulting from this condition, in order to develop helpful care.

PALABRAS CLAVE: Enfermería. Salud de la mujer. Síndrome de la inmunodeficiencia adquirida. Lactancia materna.
RESUMEN: Este estudio tuvo como objetivo desvelar el temor como modo de disposición de la mujer con el virus de la inmunodeficiencia humana en el cotidiano ante la (im)posibilidad de amamantar. Se trata de una investigación cualitativa con abordaje fenomenológico, desarrollada en el Hospital Universitario de Santa María - RS. Fueron realizadas 12 entrevistas, en el periodo de septiembre de 2004 a marzo de 2005. El análisis se realizó según el método Heideggeriano. En los resultados se registra que, a partir del descubrimiento de su condición serológica, la mujer se muestra en el modo determinado del temor en sus variaciones de pavor, horror y terror. Se concluye que en el mundo del cuidado existe la posibilidad de ayudarla en esa situación vivida, a enfrentar no sólo el diagnóstico de serología positiva, sino también las implicaciones del movimiento existencial del temor decurrentes de esa situación, buscando desarrollar un cuidado solícito.
Stela Maris de Mello Padoin

Endereço: Rua 24 de Fevereiro, 306, ap. 202

97060-580 - Nossa Senhora de Lourdes, Santa Maria, RS, Brasil

E-mail: padoinst@smail.ufsm.br
Artigo original: Pesquisa

Recebido em: 15 de janeiro de 2008 Aprovação final: 19 de agosto de 2008 


\section{CONSIDERAÇÕES INICIAIS}

A busca do estar melhor do ser-familiar e do ser-com portador do Vírus da Imunodeficiência Humana (HIV) e da Síndrome da Imunodeficiência Adquirida (SIDA) ou Adquired Immunity Deficiency Syndrome - Aids foi descrita por Padoin, em 1998, que estudou essa problemática como objeto de pesquisa de sua dissertação de mestrado, concluída na Universidade Federal de Santa Catarina (UFSC). ${ }^{1}$

A autora destacou que nesse contexto a família adoece, precisa se organizar para experienciar essa vivência e para desenvolver o processo de estar melhor, o qual poderá ser possibilitado pelas ações em Enfermagem. Esse é um momento em que o familiar se percebe como um ser que está-no-mundo-com-o-outro e que vive uma luta constante entre a razão e a emoção. ${ }^{1}$

Entende-se que é necessário e oportuno compreender os sentimentos, as emoções e os significados que o ser humano confere às situações experienciadas e às suas vivências. Assim, nos propusemos estudar a mulher com sorologia positiva para o HIV ou doente de Aids diante da (im)possibilidade da amamentação, sendo este o objeto da presente investigação.

Cabe ressaltar os avanços nas políticas públicas em relação ao Aleitamento Materno (AM) a partir da década de 1980, quando houve um novo esforço mundial que mobilizou as equipes de saúde dos serviços obstétricos e pediátricos. Esse esforço focalizava o incentivo à amamentação pautada nas vantagens oferecidas pelo leite materno em seus múltiplos aspectos, sejam eles biológicos, nutricionais, socioeconômicos e familiares.

Já na década de 1990, este incentivo surge como um movimento envolvendo a promoção, a proteção e o apoio ao AM. E, embora seja um ato natural, a amamentação é, também, um comportamento aprendido. Além disso, estudos apontavam as dificuldades apresentadas pelas mulheres nesse processo de modo que havia a necessidade de ajuda profissional e apoio familiar para a sua concretização. $^{2}$

Nesse mesmo período, surge, no mundo e no Brasil, uma nova doença transmissível e letal relacionada a grupos e comportamentos de risco. Falava-se da Aids como uma doença dos homossexuais, usuários de drogas injetáveis e homens com hemofilia. Não se esperava que as mulheres (mães em potencial) fossem se inserir nas notificações, pois não se percebiam, e também não foram consideradas, entre os grupos e os comportamentos de risco. Como conseqüência, surge a possibilidade da Transmissão Materno-Infantil (TMI) desse vírus de maneira progressiva e, em princípio, sem controle.

Para a área da saúde, em especial para o cenário de promoção, proteção e apoio ao aleitamento materno, um impasse - lidar com a mulher que até então podia e devia amamentar e agora, embora possa, não deve fazê-lo.

Entende-se que pode amamentar porque tem possibilidades biológicas de nutrir seu filho com vantagens não só já comprovadas cientificamente, como também relacionadas ao contexto socioeconômico e ao cenário de construção de vínculo afetivo. Mas não deve, porque amamentar para a mulher com sorologia positiva para o HIV, incorre na possibilidade de transmissão do vírus para a criança, o que implica um problema social e de saúde, a Aids Pediátrica. ${ }^{3-4}$

A temática amamentação e Aids aponta outras reflexões - o desafio posto com o surgimento da Aids e os avanços na implementação do paradigma pró-amamentação, desde a década de $1980 .{ }^{5}$ Com esse mesmo olhar, em uma população constituída de 67 mulheres soropositivas, em hospital público do Rio de Janeiro - RJ, em pesquisa realizada no ano de 1997, a autora entrevistou 15 gestantes incluídas no tratamento de anti-retrovirais. ${ }^{6}$ Buscou identificar os fatores que levaram as mulheres a amamentarem ou não seus filhos, considerando seus paradigmas de amamentação.

Em pesquisa desenvolvida, como tese de doutorado na UFSC, a autora além de apresentar as características sociodemográficas, reprodutivas, ônticas e psicofísicas, desvela, apoiando-se nas idéias de Merleau-Ponty, a percepção do sermulher, ser-mãe e ser mulher/mãe HIV positiva. Nos depoimentos, a mulher se percebe como uma pessoa boa, uma boa mãe, mãe protetora, apegada aos filhos/as e que "a gente nunca imagina que isso pode acontecer com a gente" .7:200

Nesse cenário, estão presentes os desafios impostos à Enfermagem, bem como a outras profissões da área da saúde, quando valoriza o cuidar de alguém que é singular em sua existência, tem possibilidade de escolhas e que é livre. Assim, percebemos a necessidade de dar voz a essas mulheres para que possamos compreendêla, a partir de sua expressão como ser-no-mundo, decorrendo a possibilidade de ajuda no modo positivo do cuidado. ${ }^{8}$ 
Então, partindo das inquietações do mundodo-trabalho, da convivência com a mulher com sorologia positiva para o HIV, o que tem sido uma vivência muito especial para nossa existencialidade como ser-no-mundo e ser-no-mundo-com-o-outro, e ancoradas no referencial teórico e metodológico de Martin Heidegger, ${ }^{8}$ desenvolvemos o presente estudo que teve como objetivo desvelar o temor como modo de disposição da mulher com HIV/Aids no cotidiano da (im)possibilidade de amamentar.

\section{METODOLOGIA}

O cenário para a produção dos dados foi o Hospital Universitário de Santa Maria - RS. Este é público, federal e de referência para assistência de pessoas com sorologia positiva para o HIV, no acompanhamento ambulatorial e tratamento daquelas que têm Aids, e também de mulheres no pré-natal e no parto. Além das crianças expostas ao HIV e aquelas em tratamento de Aids. Buscando atender a demanda do atendimento, o hospital universitário conta com o Serviço de Doenças Infecciosas Pediátricas, com o Serviço de Pré-Natal de Alto Risco e com o Serviço de Infectologia junto ao Hospital Dia. Assim, a etapa de campo desta pesquisa deu-se nestes serviços, no período de setembro de 2004 a março de 2005.

Diante das diretrizes preconizadas pela Resolução 196/96 do Conselho Nacional de Saúde, ${ }^{9}$ que trata de pesquisas com seres humanos, realizamos a tramitação do projeto junto ao Comitê de Ética em Saúde da Universidade Federal de Santa Maria, a cuja apreciação esta pesquisa foi submetida. Ainda, em cumprimento à legislação específica, foi elaborado o Termo de Consentimento Livre e Esclarecido. Após os pareceres favoráveis e a resposta às adequações solicitadas pelos referidos setores, com parecer e carta de aprovação $\mathrm{N}^{\circ}$ 089/2004, iniciamos atividades de aproximação ao cenário e de ambientação, para desenvolver a produção dos dados.

A aproximação foi o momento de estabelecer relações com as pessoas que ali se encontravam, tanto com os profissionais do serviço quanto com as depoentes. Nessa fase foi necessário criar um ambiente favorável para a entrevista fenomenológica que ocorre sob a forma de encontro existencial. E, ainda, para o movimento da ambientação, considerando o ambiente aquilo que cerca ou envolve alguma coisa ou pessoa, o meio em que se vive, o meio em que se está sendo pesquisadora e que está vivendo com o outro compartilhando sentimentos e emoções.
Na ambientação há a necessidade de um movimento, mediado pela subjetividade, no qual se percebe a singularidade, buscam-se os significados do silêncio, da fala, do dito e do não dito, procura-se respeitá-los e exercita-se a escuta. É possível que as investigadoras fiquem inquietas com o que escutam e com seus sentimentos para, então, mergulharem na difícil tarefa de redução dos pressupostos. Chegar à atitude fenomenológica de encontro com o outro, pressupõe ter clareza das inquietações e do estranhamento do sujeito pesquisador de modo a apontar obscuridades inerentes à constituição do objeto de estudo. ${ }^{10}$

O número de participantes do estudo não foi determinado previamente, considerando-se que a pesquisa é qualitativa com abordagem fenomenológica, e ainda, que se trabalha com a busca do sentido velado pelas informações e pelos significados.

Assim, foram utilizadas para análise compreensiva 12 entrevistas. Para o sigilo das depoentes, foi adotado o código M1 a M12, não sendo considerada a ordem cronológica dos encontros, tampouco o serviço onde os dados foram produzidos. Desse modo, a análise dos depoimentos deu-se sem a separação por serviço assistencial.

As mulheres que participaram da produção dos dados, tiveram sua inclusão voluntária mediante convite durante as atividades no grupo de apoio desenvolvido no ambulatório de Pediatria, Infectologia e Pré-natal. Todas concordaram com a utilização do gravador para registro das falas.

Em relação à condução da pesquisa na entrevista fenomenológica, ${ }^{11}$ entende-se que a aproximação é gradativa e necessária; que o investigador precisa perceber onde começar, o que mais o incomoda ou impede de prosseguir e o que fazer para superar as dificuldades. ${ }^{12}$ Assim, ao considerar a temática da amamentação, o contexto do cotidiano da mulher com sorologia positiva para o HIV e, principalmente, o método e a interação com a depoente, deu-se o encontro fenomenológico.

Com essa reflexão alcançamos a atitude fenomenológica esperada. ${ }^{12-13}$ Assim, a conversa iniciava com diferentes questões, oportunas ao momento do convite, considerando ter sido formulado durante as atividades de grupo ou de forma individual, até se ter a possibilidade de chegar à questão: como aconteceu a alimentação de seu filho? A partir da escuta, surgia a possibilidade de perguntar: qual foi o significado de não poder amamentar?

A opção pela pesquisa qualitativa segundo a abordagem metódica proposta por Martin Heide- 
gger, possibilitou alcançar a essência do fenômeno desvelando facetas da dimensão existencial. O sentido metodológico da pesquisa fenomenológica é a interpretação e a hermenêutica. ${ }^{14}$

Nesta metodologia a condução dos estudos impõe o desenvolvimento de dois momentos de análise. O primeiro, é um movimento compreensivo, que busca, pela redução fenomenológica, apreender e destacar o fenomenal distinguindo as suas estruturas essenciais das ocasionais de modo a constituir, a partir daquilo que é expresso, as unidades de significação e a compreensão vaga e mediana. ${ }^{9}$ As unidades de significação são apresentadas por um cabeçalho e pelos trechos significativos que tanto constroem estas estruturas como também as ilustram.

E o segundo, denominado hermenêutica, representa o movimento interpretativo que desvela o(s) sentido(s) do ser que se mostra a partir da compreensão vaga e mediana sendo direcionado pelo conceito vivido que é o fio condutor desta análise interpretativa. As estruturas essenciais são diferentes de estruturas acidentais ou ocasionais, porque são conteúdos imanentes e significativos que respondem à questão do ser e não do ente. ${ }^{9}$ Assim se dá a hermenêutica heideggeriana, que chega à compreensão e interpretação do sentido que funda o modo de ser do humano, mulheres com HIV / Aids no cotidiano da (im)possibilidade de amamentar, sujeitos da investigação em tela.

\section{RESULTADOS E DISCUSSÃO}

No primeiro momento desenvolveu-se a captação dos significados junto aos depoimentos de modo a constituir a descrição do fenômeno tal como ele se mostra. Esta descrição é feita através das estruturas de significação, seguidas pelo discurso da compreensão vaga e mediana. Aqui apresentaremos quatro unidades que anunciam a compreensão do temor como modo de disposição da mulher com HIV/ Aids no cotidiano da (im) possibilidade de amamentar.

1) Desesperadas, em pânico não aceitam o diagnóstico no momento da descoberta, porém, após, aceitam a condição de sorologia positiva para o HIV.

[...] que horror, foi muito ruim, horrível, o dia que descobri... [...] ... os quatro exame deu tudo positivo, aí tive que me conforma né ... [...] ...ésegui em frente todo mundo passa assim né, não foi fácil a paulada [...] (M6).

[...] eu não aceitei,... de jeito nenhum. não sei porque eu não aceitei, não aceitei, eu pensava só era em me mata mesmo, depois foi indo, foi indo, foi indo, foi conversando comigo que eu terminei aceitando né, não adianta [...] (M10).

[...] é difícil né, uma coisa muito difícil... [...] ... no começo foi muito, muito difícil, ah eu pensava bem vô me mata [...] (M11).

As mulheres mostram-se desesperadas no momento em que descobrem que são portadoras do HIV ou estão doentes de Aids. Elas não esperavam por isso e, no começo, não aceitam o diagnóstico, referem sua lealdade ao esposo ou companheiro, que isso foi uma decepção, pensam na possibilidade de se matar devido ao pânico da doença. Quando a descoberta se dá durante a gravidez, nos exames do pré-natal, referem que foi horrível e pensam na criança que está na barriga.

Embora no começo tenha sido muito difícil, depois elas aceitam, pensam nos filhos e filhas, em como eles vão ficar se elas morrerem e decidem que se matar não é a melhor escolha, que é necessário seguir em frente. Percebem que nada adianta, que têm que se conformar e aceitar. Algumas referem que nesse momento conversam com o companheiro e também com os profissionais da área da saúde e terminam aceitando.

2) Com medo do preconceito e da discriminação, vividos ou experienciados pelos outros, devido ao estigma da doença.

[...] Aí as gurias disse que ela é muito... com... assim... preconceito... sabe..., ela não gosta, ela sabe os probrema da minha guria, a vizinha do outro lado falou né. Então ela não deixa nem a filha dela, que é do tamanho da minha, chega perto, manda a guriazinha dela entra pra lá, entra pra dentro, vai não se encosta aí ... não se encosta... (M3).

[...] todo mundo acha que a pessoa que tem Aids é seca, é magra, e às vezes eu comento com as pessoas que falam isso, a aquela lá ta seca deve ter... porque eu perdi o meu serviço. Porque eu contei para ela isso, e ela não me quis mais. [...] contei que era soropositiva e ela [...] que ela tendo conhecimento, isso é um preconceito ignorante [...] (M4).

[...] na época de Cazuza também né, fico lembrando, eu lembro do Cazuza ainda, eu era pequena, tinha não sei, eu tinha 14 anos, eu lembro, coisa triste aquilo né como ele ficou né?(M6).

As mulheres mostram-se com medo de perder os amigos, os familiares e os filhos e as filhas. Reconhecem o preconceito e apontam as atitudes de discriminação que foram experiências de outras pessoas e aquelas que vivenciaram. Nos depoimentos, a discriminação é percebida pelo 
afastamento, referem que há pessoas que, quando sabem que elas têm a doença, se afastam. Sentem que são mal tratadas, que as crianças expostas ao HIV são afastadas das brincadeiras com seus amigos na rua ou de passeios com a família.

O estigma relacionado à Aids aparece nos depoimentos da mulheres como uma doença que marca as pessoas, para sempre, lembra a imagem de Cazuza, com dificuldade de caminhar, sem o cabelo, magro e olhos encovados. Percebem que há um equívoco, pois todos pensam que a pessoa que tem Aids é "seca", é magra, e elas se mostram com aparência saudável.

3) Com medo da doença que ameaça a vida e faz pensarem na morte e no que vai acontecer com seus filhos ou com suas filhas, elas refletem como vai ser.

[...] a gente vê as pessoa assim, no último, dai a gente dá graças a Deus de não te nada né? 'Deus o livre' eu tenho um medo de morre por causa dos meus filho, as vezes eu fico pensando...[...]... Eu tenho medo de morre e deixa minhas filha sozinhos [....] e se eu morre quemé que vai cuida?... [...] ...é brabo [...] (M9).

[...] é difícil a gente conviver com isso pensa assim, bá eu ...será que eu vou tá aqui daí a uns dias... [fica com o olhos cheios de lágrimas]... e ao mesmo tempo eu penso assim, ah mas todo mundo corre o risco de amanhã não tá aqui [...] (M11).

[...] eu não tenho nenhum problema, nem tosse, nem nada, as vezes fico roca mas é só do clima sabe até esses tempo eu fui consultar lá, mas báa dotor eu tenho medo que dê a esquemia cerebral, que deu no meu marido [...] (M12).

Assim, as mulheres revelaram que têm medo da doença. Não conhecem todos os sintomas, mas consideram horríveis, sabem que podem ter infecção, tuberculose, isquemia cerebral e que podem morrer. Já ouviram falar ou acompanharam amigos, familiares ou sabem de pessoas com Aids que já morreram.

Sentem medo de morrer por causa dos filhos e filhas. Elas refletem como vai ser, têm medo de morrer e deixar os filhos e filhas sozinhos. Perguntam-se quem vai cuidar deles, lembram dos pais, mas contrapõem que eles já não são tão novos; também têm os irmãos, mas não conseguem imaginar como vai ser.

Então, referem que se tivessem que morrer, poderia ser quando os filhos ou filhas fossem maiores, adolescentes ou adultos, porque assim já saberiam se cuidar e viver sozinhos sem depender de outras pessoas. Gostariam de deixar alguma coisa para seus filhos, adquirir alguma coisa pra eles, poderia ser o estudo, alguma coisa que ajudasse os filhos e as filhas a não passarem pelas mesmas situações por que passaram, situações relacionadas à Aids.

4) Com vivências e experiências em amamentação, mas com estranheza, dificuldade, dor e tristeza pela (im)possibilidade de amamentar. Escondem a sorologia positiva para o HIV pelo medo do que os outros vão dizer.

[...] a outra mamou no peito né. E daí essa mais na mamadeira, perdia um pouco, saia um pouco mais frio um pouco mais quente, até que acostumei a dá... [...] ... essa aqui eu estranhava sabe, volta e meia de noite assim quando ela era bem novinha, que eu, dava fome eu ia levar o peito, me dava aquele choque sabe, eu tirava de novo, aí começava a chorar, dai amamentava com a mamadeira... é ruim [...] (M2).

[...] Então não amamentei, é leite de latinha, coisa assim, também não dizia o porque, eu dizia que tinha anemia [...] ...doía muito [enquanto falava estava chorando e passando a mão no peito].[...] mas ao mesmo tempo eu ficava pensando eu não posso fazer isso porque vai prejudicar ele né, sempre tive consciência que prejudica [...]. Porque o meu outro gurizinho de seis anos, [...] ele mamou até os quatros anos [...] (M4).

[...] eu fico triste de não pode dá, e pena dela de não pode recebe mamá... [...] ...a gente nem comenta. Todos eles, são dezoito irmãos que eu tenho. E eles nem comentam nada comigo[...]. Sabem que eu tenho, mas ninguém comenta nada ...[silêncio] (M5).

As mulheres mostram-se com vivência e experiência em amamentação, na possibilidade do sim e do não, ou seja, do poder e não poder amamentar. Revelam sua experiência na convivência com as filhas e filhos, com sua família nas conversas e informações sobre o assunto com as cunhadas, mãe e sogra e nos serviços de saúde.

Nos depoimentos, para pontuarem a (im) possibilidade de amamentar, reportavam-se inicialmente à vivência com os outros filhos que puderam amamentar durante dois e até seis anos, são filhos anteriores à situação de infecção pelo HIV. Relatam que, por vezes, tinham dificuldades, apresentaram fissuras ou pouco leite e paravam de amamentar ou optavam por não amamentar devido à necessidade de trabalhar ou porque não gostavam. No entanto, após a infecção pelo HIV, ficam desesperadas, surgem a estranheza, a dor e a tristeza em não poder amamentar. Porém, mesmo com a dor e a tristeza, ao mesmo tempo pensavam que não era possível amamentar, porque prejudicaria a criança. 
A vivência da (im)possibilidade de amamentar despertou a possibilidade da amamentação. As depoentes revelam que agora, quando vêem alguém amamentando, têm vontade de dar o peito, agora que não podem. Ao vivenciarem a (im)possiblidade de amamentar seus filhos, mostram-se com medo de revelar o diagnóstico, com medo do que os outros vão dizer. Para esconder a sorologia positiva ao HIV, respondem aos questionamentos ou comentários com omissões, não falando nada, ou não sabem o que vão dizer ou, ainda, justificam o fato de não amamentar com condicionantes associados ao uso de medicações ou patologias comuns, como a anemia.

\section{A compreensão do temor como modo de disposição}

No segundo momento metódico, temos como fonte para a análise interpretativa o discurso das mulheres, que "deve ser compreendido inicialmente como falar com o outro no e para o agir e atuar com o outro" ou ainda, "discutir-um-como-outro", ${ }^{15: 39}$ oportunidades, planos, eventos e/ou circunstâncias do mundo da vida. O fio condutor da hermenêutica constitui o conceito vivido que é formado pelo cabeçalho das unidades de significação anteriormente apresentadas.

Através deste fio condutor desvela-se o sentido, que é aquilo que se articula na interpretação e que já foi originariamente articulado no discurso da compreensão vaga e mediana, que é a articulação em significações as quais sempre têm sentido. ${ }^{8: 219} \mathrm{O}$ discurso é tudo que eu sou, como eu me mostro e como me expresso, é o que possibilita o desvelar do quem dotado de pre-sença. Neste estudo, o sentido foi captado e entendido como o modo singular das mulheres com HIV/Aids, que diante da (im)possibilidade de amamentar compreenderam e significaram o seu mundo.

Percebemos, no discurso das mulheres, que aquilo que vem ao encontro, a partir da descoberta da infecção pelo HIV, desperta na mulher modos de disposição. ${ }^{8} \mathrm{O}$ termo disposição é, onticamente, mais conhecido como o estado de humor, considerando este fenômeno como um existencial fundamental. O humor revela "como alguém está e se torna. É nesse 'como alguém está' que o humor conduz o ser para o seu 'pre'", ,:188 refere-se à abertura essencial.

O fato de a pre-sença se descobrir entregue à responsabilidade do 'pre', Heidegger chama de estar-lançado, que deve indicar a facticidade de ser entregue à responsabilidade, ou seja, "o fato de ser e ter de ser". Então, o mundo que já se abriu deixa e faz com que o ente intramundano venha ao encontro, no modo da ocupação dotada de uma circunvisão. Assim, poderá aquilo que vem ao encontro ter o caráter de ser atingido. 8:191

Neste estudo, o que vem ao encontro da mulher é a sua aproximação com a infecção pelo HIV e a Aids e também todas as suas implicações no mundo da vida. Então, dotadas de uma circunvisão cotidiana acerca da epidemia e a partir da descoberta de sua condição sorológica, em seu discurso a mulher mostra-se no modo determinado do temor. ${ }^{8}$

Temerosa, ela pensa na possibilidade de se matar devido ao medo da doença, mostra-se desesperada. A mulher fala do medo, do pânico, do pavor. Esses sentimentos são modos existenciais, e o humor "designa o estado e a integração dos diversos modos de sentir-se, relacionar-se e de todos os sentimentos, emoções e afetos" . $^{8: 321}$

Como modo da disposição, o fenômeno do temor poderá ser analisado na perspectiva de "o que se teme, o temer e pelo que se teme" ${ }^{8: 195}$ Assim, no temor, o que se teme, o 'temível', é como algo que possui o caráter de ameaça, possui o modo conjuntural do dano, que se mostra dentro de um contexto. Este é sempre um ente que vem ao encontro dentro do mundo e que possui o modo de ser do manual, ou do ser simplesmente dado ou, ainda, ser-com.

Aqui temos a Aids como temível envolta em um contexto de preconceito, discriminação, doença e morte, "como um 'estranho' conhecido, na verdade ainda não, mas a qualquer momento sim" . 8:195 O temível apareceu no discurso das mulheres como as manifestações da Aids, que ameaçam a rotina, que promovem o aspecto do dano, da pessoa magra, feia, sem cabelos, ou seja, nas marcas e no estigma, de que já ouviu falar como aquelas manifestações apontadas na pessoa de Cazuza, ou que já experienciou junto com seu familiar que morreu de Aids ou conhecidos.

Para Heidegger, "apenas o ente em que, sendo, está em jogo seu próprio ser, pode temer" 8:196 Então, pelo que se teme, é o que é ameaçador, é aquilo que está em risco, podendo ser a própria existência ou ainda a ameaça da convivência com o outro. Devido ao que ouviram falar acerca da evolução da doença, das pessoas que se infectam com o vírus e, principalmente, aquilo que sabem acerca do preconceito e da discriminação sofridos pelas pessoas soropositivas, o próprio temer libera a ameaça. 
O temer pode também se estender a outros; nesse caso, a mulher pensa no(a) filho(a) e em como vai ser. Esse temer em lugar do outro, na maior parte das vezes, acontece quando o outro não teme. Temer em lugar do outro é um modo de disposição junto com os outros, é um "sentir-se atemorizado", não como graus de 'sentimentos' e, sim como modos existenciais, desencadeando "necessidade de recompor-se" ${ }^{8: 196-7}$

No entanto, surgem diferentes possibilidades de ser do temer, considerando que os momentos constitutivos de todo o fenômeno do temor podem variar, na medida em que uma ameaça poderá se apresentar como 'sim' a qualquer momento, ou a ameaça "subitamente se abate sobre o ser-nomundo da ocupação, o temor se transforma em pavor" .197 Desvela-se no discurso quando relata o momento em que descobre o diagnóstico de sorologia positiva e fica desesperada, expressando a vontade de se matar. Ou seja, a referência do pavor é, de início, algo conhecido e familiar, sendo o modo de encontro com a ameaça de modo súbito.

Este conhecido e familiar se mostra no discurso da mulher. A Aids lhe é familiar, pois dela já ouviu falar, porém, ela não assume para si esta possibilidade. Mas quando subitamente ela se descobre infectada, a disposição se modifica, e a mulher se mostra no modo de ser do pavor.

Vimos, neste estudo, que a infecção pelo HIV é algo de que ela já ouviu falar e que passou a ser familiar para a mulher, faz parte de seu dia-adia, pois está instalada. Embora com dificuldade, agora ela aceita. Ela mantém seu relacionamento conjugal, ou tem um novo relacionamento, e então ela fica grávida.

Sabemos que a mulher que está grávida, por opção ou não, assim está porque não usou preservativo na relação sexual. Logo, teve ou tem, com freqüência ou não, relações sexuais sem proteção, gerando uma situação de risco à infecção pelo HIV. Tal situação faz parte do falatório de todos e torna tanto a gestação como a Aids, familiares. ${ }^{8}$ Também é familiar que toda a mulher tenha filhos e possa amamentar sua criança ao nascer, ou a mulher ter filhos e amamentar, além de ser esperado, é conhecido como um dever de toda mulher. Por outro lado, a situação de não amamentar é uma pista para se pensar na possibilidade de aquela mulher ser HIV positiva, pois já está se tornando conhecida pela interpretação pública a relação entre o HIV e a (im)possibilidade de amamentar.

Porém, se ao contrário, o que ameaça possuir o caráter de algo totalmente não familiar, o temor transforma-se em horror. Percebeu-se que esse modo de disposição se mostra quando o que vem ao encontro é a situação da (im)possibilidade de amamentar, o que não é familiar para a mulher, uma vez que expressam familiaridade com a amamentação em suas experiências e vivências anteriores à infecção pelo HIV ou ainda pelo que elas já ouviram falar acerca de amamentar.

Possuindo ao mesmo tempo o caráter do súbito modifica-se o horror, e o seu discurso passa a ter o sentido do terror. Somente quando o que ameaça vem ao encontro como algo não familiar, ou seja - o horror -, possuindo ao mesmo tempo o caráter de súbito, a saber - o pavor, é que se constitui o modo de disposição do terror. ${ }^{8} \mathrm{O}$ que caracteriza o temor, o temível, a ameaça ou o dano pressuposto nesta situação não é a privação do ato de amamentar e as implicações para a saúde da criança e da mulher, mas sim a possibilidade de a (im)possibilidade de amamentar ameaçar o sigilo, o pacto de silêncio ${ }^{1} \mathrm{e}$, assim, dar-se a descoberta do diagnóstico pelos outros.

Dessa forma, a possibilidade da revelação do diagnóstico que a (im)possibilidade de amamentar traz para esta mulher será o temível. Para ela, esse momento após o parto, em que ela está diante da (im)possibilidade de amamentar, é descrito como muito difícil, horrível, ela fica desesperada, pois vai todo mundo falar. Diante desta possibilidade, mais uma vez o que teme é a discriminação e o preconceito.

Ao descrever essas modalidades do temor, entre outras, Heidegger declara todas as modificações do temor como possibilidade da disposição, a qual aponta para o fato de que a pre-sença, como ser-no-mundo, é "temerosa". "Essa 'temerosidade' não deve ser compreendida ônticamente no sentido de uma predisposição fatual e 'singular', mas como uma possibilidade existencial da disposição essencial de toda pre-sença" . 8:197

O que o pavor, o horror e o terror como variações do temor mostram essencialmente é o movimento de aproximação com a possibilidade de ser portadora do HIV, até o momento em que esta possibilidade se dá como facticidade e o movimento de aproximação com a public-idade de seu diagnóstico ou de seu(s) filhos(as). Isso de dá tanto no momento do diagnóstico quando a mulher se descobre infectada, quanto na gestação quando a mulher inicia o uso da medicação anti-retroviral, e renovar-se-á no cotidiano de mulher-mãe a cada momento que estiver diante da situação da (im) possibilidade de amamentar. 


\section{CONSIDERAÇÕES FINAIS}

Pudemos compreender, diante das vivências junto-com a mulher com sorologia positiva para o HIV e com base no conhecimento prévio da ciência acerca da epidemia da Aids e da contradição posta para os profissionais em relação ao movimento pró-amamentação, que este estudo desvelou o temor como modo de disposição da mulher diante da (im)possibilidade de amamentar.

A análise mostrou que, embora de início a mulher fique em pânico, com o tempo ela aceita, mostrando que o ser se compreende a partir de sua temporalidade. Ela, em seu mundo da vida, mostra sua familiaridade e sua circunvisão acerca da amamentação, fala de suas experiências com os outros e de suas vivências em amamentar. Por outro lado, mostra estranheza e dificuldade na situação de (im)possibilidade de amamentar, mostra a amamentação no modo da surpresa, pois aquilo que está à mão não pode ser usado e está simplesmente presente. Nesse momento, quebram-se os nexos referenciais em relação à amamentação, e ela mostra que não tem familiaridade com a (im) possibilidade de amamentar.

Nesse sentido, a Aids e a possibilidade de a (im)possibilidade da amamentar revelam sua condição de ser portadora de HIV e têm o caráter de ser temível. Assim, pela temerosidade, ela se mantém no silêncio, prefere o não dito em relação à sua condição sorológica, pois o pior será a situação de ser julgada e considerada culpada mediante atitudes de discriminação e preconceito de que já ouviu falar ou até mesmo já vivenciou. Assim, ela se mantém dominada pelo impacto do diagnóstico e pelo medo do preconceito e da discriminação porque a (im)possibilidade de amamentar é para ela algo não familiar e denunciante de sua condição de ser portadora de um vírus letal.

No modo temeroso, a mulher se mostra como ela não é, e se mantém ocupada com a síndrome. Nessa ocupação permeada pelo temor e pela impessoalidade, ela também não se mostra. Assim, suas circunstâncias individuais e sociais e sua condição de ser portadora são ocultadas de seus familiares e, por vezes, de seu companheiro sexual. Para algumas, será apenas no serviço de saúde que ela falará acerca da exposição à infecção e da situação de ser portadora do HIV ou doente de Aids.

Percebemos, então, que as políticas públicas, aquelas que se referem ao AM, estão assentadas em estratégias que promovem o AM para todas as mulheres, ignorando a possibilidade de a mulher ser portadora do HIV. “Olham” para a mulher sem considerar as circunstâncias individuais e sociais que as aproximam da epidemia ou sua condição de portadora do HIV. Desenvolvem estratégias de proteção e de apoio para a mulher que pode e decide amamentar.

A mulher contribui apontando, neste estudo, a necessidade de um apoio mediado pelo diálogo, um cuidado calcado na solicitude, um cuidado que possibilite a mulher sair do "eles", sair do "a gente" para ser si mesma. Será preciso valorizar na implementação de uma política pública, seja no controle da Aids ou no AM, o desenvolvimento de um cuidado solícito, pautado na relação do ser-com autêntico, que possibilite a abertura, que possibilite à mulher a compreensão de com o quê e para que se ocupar em seu cotidiano.

Isso nos leva a perceber que as dificuldades da mulher e as necessidades de ajuda estão focalizadas muito mais no âmbito social das relações com-o-outro-no-mundo. Conclui-se pela valorização das relações humanas mediando o processo de interação profissional de saúde e mulher conforme previsto nas estratégias assistenciais de acolhimento e aconselhamento necessárias tanto na abordagem da problemática do HIV/Aids quanto na proposta de promoção, proteção e apoio à amamentação.

Entendemos que no mundo do cuidado, na dinâmica de cuidar, no encontro vivido e dialogado, será a partir da compreensão do modo-deser da mulher, que dar-se-á a possibilidade de ajudá-la nessa situação vivida de enfrentar não só o diagnóstico de sorologia positiva para o HIV diante da (im)possibilidade de amamentar, como também as implicações do movimento existencial do temor decorrentes desta condição sorológica, para estar-com-ela, buscando desenvolver um cuidado solícito.

\section{REFERÊNCIAS}

1 Padoin SMM. Em busca do estar melhor do ser-familiar e do ser-com AIDS. [dissertação]. Florianópolis (SC): Universidade Federal de Santa Catarina. Programa de Pós-Graduação em Enfermagem; 1998.

2 Souza IEO. O desvelar do ser-gestante diante da possibilidade de amamentação. [tese]. Rio de Janeiro(RJ): Universidade Federal do Rio de Janeiro. Escola de Enfermagem Ana Nery. Programa de PósGraduação em Enfermagem; 1993.

3 Della Negra M, organizadora. Manejo clínico da AIDS pediátrica. São Paulo (SP): Atheneu; 1997. 
4 Rubini N. AIDS pediátrica. J Bras Med.1997 Dez; edição especial:27-30.

5 Rea MF. Reflexões sobre a amamentação no Brasil: de como passamos a 10 meses de duração. Cad Saúde Pública. 2003 Dez; 12(S1):S37-45.

6 Esteves TMB. Olhando o passado e repensando o futuro: a desconstrução do paradigma da amamentaçãoem relação ao vírus da imunodeficiência humana na transmissão vertical. [dissertação]. Rio de Janeiro(RJ): Universidade Federal do Rio de Janeiro. Escola de Enfermagem Alfredo Pinto; 2000.

7 Santos EKA. A expressividade corporal o sermulher/mãe HIV positiva frente à privação do ato de amamentar: a compreensão do significado pela enfermeira à luz da teoria da expressão de MerleauPonty. [tese]. Florianópolis (SC): Universidade Federal de Santa Catarina. Programa de PósGradução em Enfermagem; 2004.

8 Heidegger M. Ser e Tempo. Parte I. $6^{\text {a }}$ ed. Petrópolis (RJ): Vozes; 1997.

9 Ministério da Saúde (BR), Conselho Nacional de Saúde, Comissão Nacional de Ética em Pesquisa. Resolução N $^{\circ} 196$ de 10 de outubro de 1996: diretrizes e normas regulamentadoras de pesquisa em seres humanos. Brasília (DF): MS; 1996.

10 Neves EP, Souza IEO. Pesquisa em Enfermagem: buscando resgatar a posição do sujeito que a desenvolve. Texto Contexto Enferm. 2003 Jul-Set; 12(3):387-93.

11 Carvalho AS. Metodologia da entrevista: uma abordagem fenomenológica. Rio de Janeiro (RJ): Agir; 1987.

12 Simões SMF, Souza IEO. Um caminhar na aproximação da entrevista fenomenológica. Rev Latino-am. Enfermagem. 1997 Jul-Ago; 5(3):13-7.

13 Terra MG, Camponogara S, Santos EKA, Souza AIJ, Erdmann AL. Na trilha da fenomenologia: um caminho para a pesquisa em enfermagem. Texto Contexto Enferm. 2006 Out-Dez; 15(4):672-8.

14 Souza IEO, Simões SMF. O método fenomenológico Heideggeriano como possibilidade na pesquisa em enfermagem. Texto Contexto Enferm. 1997 Set-Dez; 6(3):50-6.

15 Figal G. Martin Heidegger: fenomenologia da liberdade. Rio de Janeiro (RJ): Forense Universitária; 2005. 